\title{
Fiber Treatment and Loading Affect Mechanical Properties of Bamboo/Cement Composite
}

\author{
Serbini Noorul Zatul ${ }^{1}$, Kim S. Siow ${ }^{2}$, Abu Samah Zuruzi ${ }^{1}$
}

\begin{abstract}
The effect of fiber treatment and loading on the mechanical properties of bamboo/cement composite was investigated. Compression tests and three-point bend tests were carried out on bamboo fiber reinforced cement specimens after 10day aging to evaluate effects of fiber addition on mechanical properties. Initial results indicate that bamboo fiber treatment and loading significantly affect mechanical properties of cement. Cement reinforced with treated bamboo fibers has better mechanical properties than those reinforced with as-received fibers which are untreated. In addition, mechanical properties of cement degrade beyond a threshold fiber loading.
\end{abstract}

Index Terms-Bamboo, cement, fibers, mechanical properties

\section{INTRODUCTION}

Steel is the most widely used reinforcement material in cement. A report published by the World Steel Association in 2012 states that $51.2 \%$ of the global steel production goes into construction [1]. Steel production is costly, produces carbon dioxide and is energy intensive. Advancement in technology in the steel industry reduced energy consumption during steel production by $60 \%$ over the past 50 years. Nevertheless, 20 GJ of energy is consumed and 20 tonnes of carbon dioxide gas is emitted for every tonne of steel cast [1]. Alternative reinforcement materials which are more environmentally friendly and less costly relative to steel are highly desired. Natural plant based fibers have been investigated as reinforcement materials in composites [2]. They are ecologically sustainable, inexpensive to process and readily available.

Bamboo plants typically require a few months to reach maturity and about 3 to 5 years for its culm to attain satisfactory mechanical properties. In addition, bamboo is ubiquitous in tropical regions including Brunei and can be found in abundance the year whole year. Bamboo culms have been used in construction in many Asian societies due to its low cost, accessibility and robustness. In Brunei, bamboo has been used as scaffolding and constructing simple residential structures. It is also used as contain food during processing and to make handicrafts. Bamboo is a source of ecologically sustainable material.

\footnotetext{
${ }^{1}$ Mechanical Engineering Programme, Universiti Teknologi Brunei, Gadong, BE 1921 Brunei Darussalam

2 Institute of Microengineering and Nanoelectronics, Universiti Kebangsaan Malaysia, 43600 Bangi, Selangor, Malaysia.
}

Bamboo possesses tremendous engineering value that has not been realized. Bamboo has a compressive strength of between 62-93 MPa while that for both residential and high strength cement are between 17-28 $\mathrm{MPa}$ and $70 \mathrm{MPa}$, respectively [3]. Also, bamboo has higher Ashby's merit index based on strength per unit mass; it has a tensile strength of $0.37 \mathrm{MPa} /(\mathrm{kg} / \mathrm{m} 3)$ compared to $0.021 \mathrm{MPa} /(\mathrm{kg} / \mathrm{m} 3)$ of many types of steel. [4].

Bamboo as a reinforcement has been widely studied. In most of these studies, bamboo used was in the form of strips and culms [5]. In addition, gravel was added that complicates analysis of fiber/cement interactions. Relatively fewer research have been done using bamboo fibers in cement [6]. The objective of this research is to investigate the mechanical properties of cement reinforced with bamboo fibers. In addition, the effect of treatment on the mechanical properties of fiber reinforced cement is investigated.

\section{EXPERIMENTAL PROCEDURE}

\section{A. Materials and Equipment}

In this study, bamboo plants between 3 to 6 years old with a diameter of about $50 \mathrm{~mm}$ were used. Only healthy bamboo plants without any disease symptoms were chosen. The cement used in this study was Brunei Ordinary Portland cement which is commonly used for construction. The aim of this study is to elucidate the interaction between fibers and cement. Hence, sand and rocks were not added to the fiber cement mix. Specimens were tested using an Instron testing machine.

\section{B. Fiber Preparation}

To obtain bamboo fibers, bamboo strips were fed into a rolling machine. The rolling machine flattens these strips into smaller fibers. The bamboo fibers obtained were divided into two portions.

The first portion was put through a treatment process. In this process, fibers were boiled for 5 hours in water at normal atmospheric pressure. After boiling and once it has cooled down to room temperature, these fibers were then dried for 10 minutes at $100^{\circ} \mathrm{C}$ in an oven; such fibers are labelled as mechanical treated (MT). The second portion of bamboo fibers was used without further processing. This untreated portion is labelled "as-received" (AR) condition. Bamboo fibers used in this study are about $5 \mathrm{~mm}$ long. 


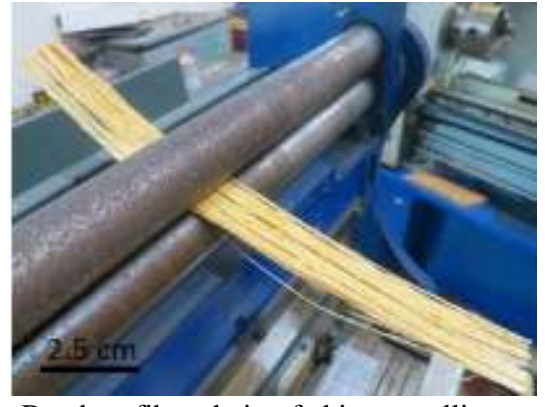

Fig. 1. Bamboo fibers being fed into a rolling machine

\section{Bamboo Fiber Reinforced Cement (BFRC)}

Bamboo fiber reinforced cement specimens used in this study were prepared from cement to water mix ratio of 2.5:1 by mass. Different loadings of bamboo fibers used were. For each loading, bamboo fibers were weighed and the appropriate amounts added to the cement water mix. To obtain a consistent and uniform mix, the mixture of bamboo fibers and cement was stirred until the fibers were dispersed uniformly. The loadings used in this study are $0.25 \%$ and $0.50 \%$ by mass. Control specimens with no fiber loading were also prepared as comparison to elucidate the effect of bamboo fiber addition.

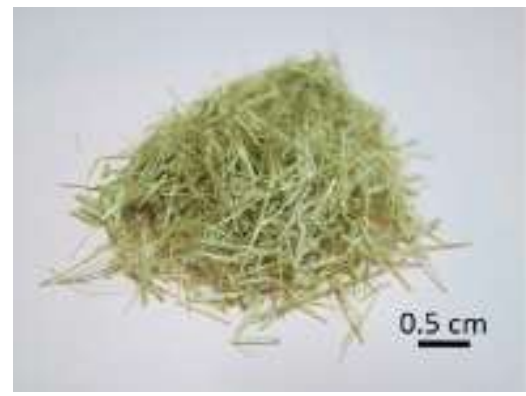

Fig. 2. Bamboo fibers

Cylindrical polyvinyl chloride (PVC) molds were used as molds to form compression and three-point bend test specimens. Homogeneous bamboo fiber cement mix obtained was then poured into appropriate molds to set. Molds to prepare compression test specimens were cylinders with 38.1 $\mathrm{mm}$ and $50 \mathrm{~mm}$ inner diameter and length, respectively. Dimension of molds for three-point bend test is $38.1 \mathrm{~mm}$ and $200 \mathrm{~mm}$ inner diameter and length, respectively. After the mix has been poured into molds, the specimens were compacted for $1 \mathrm{~min}$ to reduce voids. The mix was allowed to cure and was stored at room temperature $\left(25^{\circ} \mathrm{C}\right)$ for 10 days prior to testing. In general, specimens have smooth surface with uniform coloration and minimal voids.
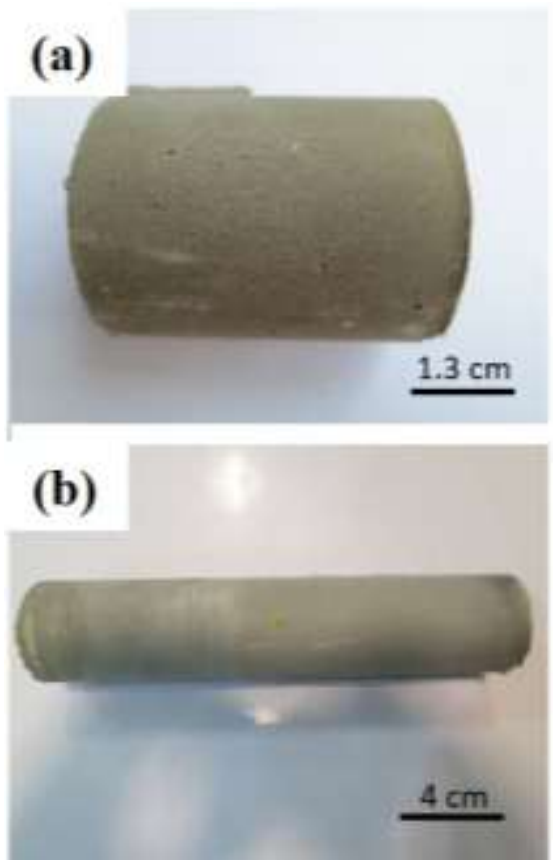

Fig. 3. BFRC specimens: (a) Compression specimen; (b) Three-point bend specimen

\section{TEST METHODS}

\section{A. Compression Test}

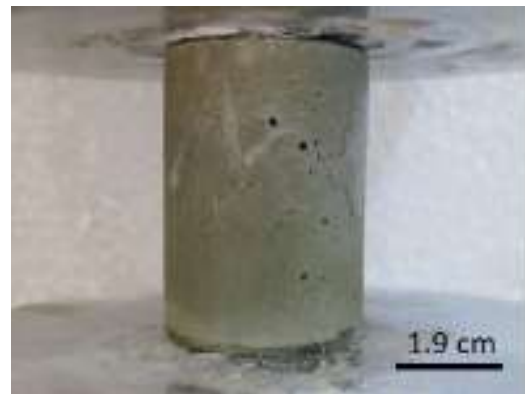

Fig. 4.BFRC during compression test

A loading rate of $12 \mathrm{MPa} / \mathrm{min}$ was used during compression test. Specimens were placed between steel platens in an Instron machine and compressed until failure; see Fig. 4 below.

\section{B. Three-point Bend Test}

Figure 5 shows geometry of the three-point bend test. A specimen is supported by two bottom point contacts spaced $140 \mathrm{~mm}$ apart below the specimen. A top point contact located midway between the two point contacts applies a downward strain at a rate of $0.02 \mathrm{~mm} / \mathrm{s}$. The top point contact is directly above a notch that had been machined into the specimen. Specimens were tested until failure. 


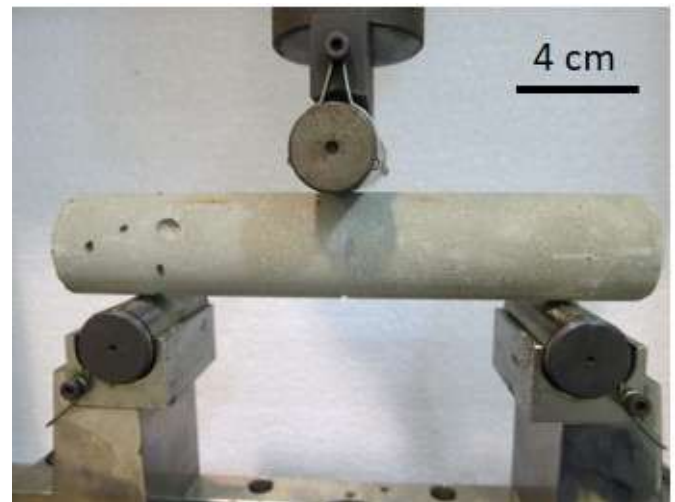

Fig. 5.BFRC during three-point bend test

\section{RESULTS AND DISCUSSION}

The average compressive strength (CS) and elastic modulus (EM) for are shown in Table 1 below.

TABLE I: RESULTS OF COMPRESSION TEST

\begin{tabular}{|c|c|c|c|c|}
\hline \multirow{2}{*}{$\begin{array}{c}\text { Fiber } \\
\text { Loading } \\
\% \\
\end{array}$} & \multicolumn{2}{|c|}{$\overline{\mathrm{ARR}}$} & \multicolumn{2}{|c|}{ MT } \\
\hline & $\begin{array}{l}\mathrm{CS}, \\
\mathrm{MPa}\end{array}$ & $\begin{array}{l}\mathrm{CM}, \\
\mathrm{MPa}\end{array}$ & $\begin{array}{l}\mathrm{CS}, \\
\mathrm{MPa}\end{array}$ & $\begin{array}{l}\mathrm{CM}, \\
\mathrm{MPa}\end{array}$ \\
\hline 0.00 & 22.2 & 923 & 22.2 & 923 \\
\hline 0.25 & 22.1 & 633 & 25.4 & 1167 \\
\hline 0.50 & 13.4 & 557 & 24.9 & 1,944 \\
\hline
\end{tabular}

Addition of bamboo fibers affects the mechanical properties during compression. Treated bamboo fibers significantly improve strength and modulus during compression. When AR fibers are added, compressive strength remains the same at $0.25 \%$ loading and degrades when loading is increased to $0.5 \%$. The elastic modulus for cement composites loaded with $0.25 \%$ and $0.50 \%$ AR fibers are lower than that for pure cement.

In contrast, the compressive strength increased from 22.2 $\mathrm{MPa}$ for pure cement to 25.4 MPa and 24.9 $\mathrm{MPa}$ for cement composites with $0.25 \%$ and $0.50 \%$ MT fiber additions. The elastic modulus for cement composites loaded with $0.25 \%$ and $0.50 \%$ MT fibers are higher than that for pure cement as well.

These results indicate addition of bamboo fibers affect the mechanical properties of cement composites. Addition of treated bamboo fiber improves the mechanical properties of cement composites during compression. Addition of untreated bamboo fibers at loading levels in the present study does not result in noticeable improvement in mechanical properties.

According to a similar study, natural fibers increase the uniaxial compression strength to cement composite due to the fibers crossing micro / macro cracks present in the cement composite. This strengthening mechanism depends on the interconnected and other factors such as fiber geometry and loading [7].

The average flexural strength (FS) and flexural modulus (FM) for three-point bend test are shown in Table 2 below.
TABLE II: RESULTS OF THREE-POINT BEND TEST

\begin{tabular}{ccccc}
\hline \hline $\begin{array}{c}\text { Fiber } \\
\text { Loading } \\
\%\end{array}$ & \multicolumn{2}{c}{ AR } & \multicolumn{2}{c}{ MT } \\
\hline & FS, & FM, & FS, & FM, \\
& $\mathrm{MPa}$ & $\mathrm{MPa}$ & $\mathrm{MPa}$ & $\mathrm{MPa}$ \\
0.00 & 3.2 & 3966 & 3.2 & 3966 \\
0.25 & 4.4 & 8743 & 4.5 & 8030 \\
0.50 & 4.5 & 6420 & 3.2 & 5066 \\
\hline
\end{tabular}

In general, addition of bamboo fiber increases the flexural strength and elastic modulus of cement composites. When AR bamboo fibers are added, the flexural modulus increases by more than $100 \%$ at $0.25 \%$ loading and by $62 \%$ at $0.50 \%$ loading. Flexural strength increases from $3.2 \mathrm{MPa}$ to about 4.4 $\mathrm{MPa}$ and $4.5 \mathrm{MPa}$ at $0.25 \%$ and $0.50 \%$ AR fiber loading, respectively.

Flexural strength and flexural modulus are also enhanced when treated fibers are added. It was observed that flexural strength and flexural modulus at $0.25 \%$ MT fiber loading are the highest. These values drop at $0.50 \% \mathrm{MT}$ fiber loading.

Compressive and flexural strength values obtained in the current study are comparable to values reported in the literature. Terai and Minami reported that cement composites loaded with $1 \%$ bamboo fibers have compressive strength and flexural strength of $8.3 \mathrm{MPa}$ and $2.5 \mathrm{MPa}$, respectively at a fiber loading of $1.0 \%$ [8]. The study had also the same decreasing compressive and flexural strengths at increasing fiber loading. It must be noted however, that Terai and Minami added gravel in addition to bamboo fiber to cement.

SEM images of as received and treated bamboo fibers are shown in Figure 6. Morphologies of these fibers are different. It can be observed that surface of as-received fibers is smoother and decorated with irregular shaped flakes. In contrast the treated fibers are rougher with uniform rectangular shaped flakes. It is believed that this difference in morphology contributes to the difference in mechanical properties in cement composites observed.
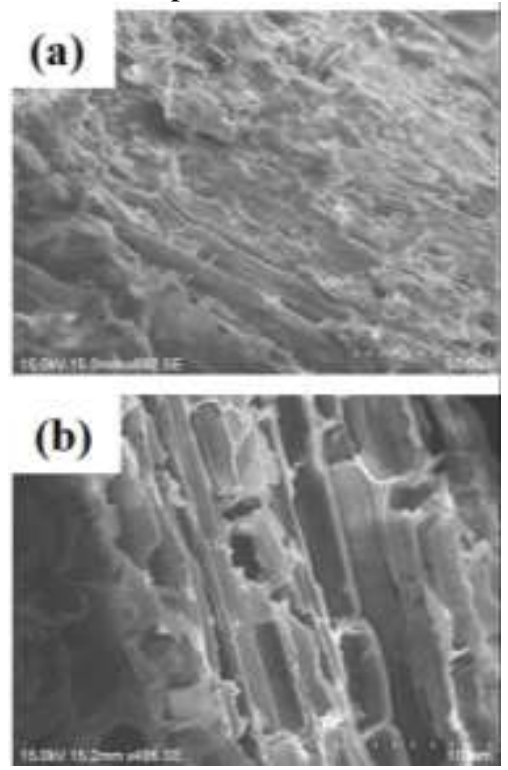

Fig. 6.SEM image of BFRC: (a) As-received specimen; (b) MT specimen 


\section{CONCLUSION}

Bamboo fiber preparation and loading have significant effect on mechanical properties of bamboo fiber reinforced cement composites. Compressive strength and elastic modules of cement composites reinforced with AR fibers were lower than those of pure cement specimens. In contrast, mechanical properties of cement composites reinforced with MT fibers are superior during compression. In general, bamboo fiber addition improves mechanical properties during three-point bend test. It was observed that elastic modulus at $0.25 \%$ loading of MT and AR fibers are high and decreases for $0.50 \%$ loading.

\section{ACKNOWLEDGMENT}

The authors acknowledge Mr Kamarudjaman Bin Abu Bakar and Mr Hj. Md. Abu Yazid Bin Hj. Awang Damit for their assistance with the mechanical testing.

\section{REFERENCES}

[1] World Steel Association, "Sustainable Steel: Policy and Indicators," 2014.

[2] T. Paramasivam and A. P. J. Abdul Kalam, "On the study of indigenous natural-fibre composites," Fibre Science and Technology, vol. 7, no. 2, pp. $85-88,1974$. https://doi.org/10.1016/0015-0568(74)90020-7

[3] NRMCA. (2003). CIP 35 - Testing Compressive Strength of Cement. Cement in Practice. [Online]. Available: http://www.nrmca.org/aboutcement/cips/35p.pdf

[4] T. Gutu, "A Study on the Mechanical Strength Properties of Bamboo to Enhance Its Diversification on Its Utilization," International Journal of Innovative Technology and Exploring Engineering, vol. 2, no. 5, pp. 314, 2013.

[5] K. Ghavami, "Bamboo as reinforcement in structural concrete elements," Cement \& Concrete Composites, vol. 27, p. 637-649, 2005. https://doi.org/10.1016/j.cemconcomp.2004.06.002

[6] R. S. P. Coutts and Y. Ni, "Autoclaved bamboo pulp fibre reinforced cement," Cement and Concrete Composites, vol. 17, no. 2, pp. 99-106, 1995. https://doi.org/10.1016/0958-9465(94)00002-G

[7] N. Cristelo, V. M. Cunha, M. Dias, A. T. Gomes, T. Miranda and N. Araujo, "Influence of Discrete Fiber Reinforcement on the Uniaxial Compression Response and Seismic Wave Velocity of a CementStabilised Sandy-clay," Geotextiles and Geomembranes, vol. 43, pp113, 2015. https://doi.org/10.1016/j.geotexmem.2014.11.007

[8] M. Terai and K. Minami, "Basic Study on Mechanical Properties of Bamboo Fiber Reinforced Cement," Global Thinking In Structural Engineering: Recent Achievements, vol. 8, pp. 17-24, 2012.

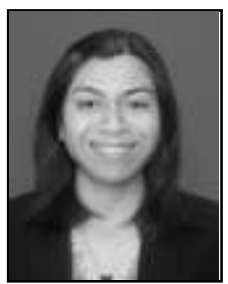

Born in Brunei Darussalam, in 1988, Serbini. Noorul Zatul received the Higher National Diploma in mechanical engineering in 2011 and the B.Eng (Hons) in mechanical engineering in 2016; all from the Universiti Teknologi Brunei. She is currently a graduate student in Mechanical Engineering Program Area, Universiti Teknologi Brunei.

Prior to her undergraduate studies in 2012, she was an engineering apprentice in Brunei Liquefied Natural Gas Sdn. Bhd. Her research is focused on development of natural fibers as an alternative sustainable resource for engineering applications such as in construction.

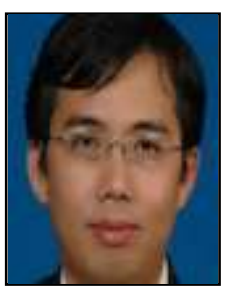

Kim Shyong. Siow was born in Malaysia, in 1973. He received the B.A.Sc.(Hons) and M.A.Sc both in materials engineering from the Nanyang Technological University, Singapore, in 1997 and 2000, respectively. He obtained his Ph.D. degree in plasma processing of biomaterials from University of South Australia, in 2007. He is currently a Research Fellow / Senior Lecturer in the Institute of Microengineering and Nanoelectronics, Universiti Kebangsaan Malaysia (UKM).

Prior to joining UKM, he worked as a materials engineer at multi-national companies and the National University of Singapore, and a technology transfer officer at the commercialization arm of Agency for Science, Technology and Research, (Singapore). His research interests are related to surface modification using plasma technologies for biomaterials, adhesion, anti-bacterial/microbial and microfluidic applications, and joining technologies using sintered silver.

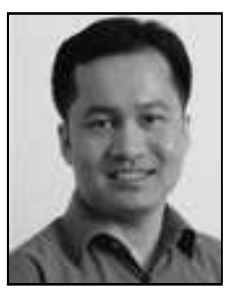

Abu Samah. Zuruzi was born in Singapore, in 1972 $\mathrm{He}$ received the B.ASc.(Hons) in materials engineering from Nanyang Technological University, Singapore, in 1997 and the Ph.D. degree in materials from University of California, Santa Barbara, CA, in 2005. He is currently a Professor in the Mechanical Engineering Program Area, Universiti Teknologi Brunei.

From 1997 to 2000, he was a Research Officer with the Institute of Materials Research and Engineering, Agency for Science, Technology and Research, Singapore. He conducted postdoctoral studies at Agilent Laboratories, Palo Alto CA, and subsequently worked as a Senior Engineer for Intel Inc, Chandler, AZ. He was a Senior Lecturer at Nanyang Polytechnic until 2011 and at Singapore University of Technology and Design until 2015. His research interests include materials and process development for sustainability, joining technologies and microsystems.

He has won various awards including the Institution of Engineers, Singapore Outstanding Volunteer Award in 2014 and International Fellowship from the Agency for Science Technology and Research, Singapore. He is an inventor on 3 United States patents. 